\title{
Participação consultiva no Brasil: o caso do Conselho da Cidade de São Paulo
}

Fernanda Lima-Silva 1

Kate Abreu 1

Esther Leblanc 1

${ }^{1}$ Fundação Getulio Vargas (FGV EAESP) / Escola de Administração de Empresas de São Paulo, São Paulo / SP — Brasil

Este artigo tem como objeto analítico o Conselho da Cidade de São Paulo, um canal inovador de comunicação entre a sociedade civil e o executivo municipal. Esta pesquisa exploratória é baseada em um estudo de caso intrínseco, tendo como objetivos compreender o funcionamento desse conselho e relacioná-lo a outras instituições participativas no Brasil. Para isso, foram realizadas entrevistas semiestruturadas com conselheiros(as) e representantes da gestão municipal, observação participante em reuniões do comitê gestor e análise de documentos oficiais. Os dados foram analisados a partir da teoria sobre democracia deliberativa e de estudos sobre conselhos participativos. Os resultados apontam que o Conselho da Cidade de São Paulo está parcialmente alinhado ao modelo deliberativo de democracia, e fortemente aos exemplos federal e estadual de Conselhos de Desenvolvimento Social e Econômico. Pelas especificidades dessas instâncias, sugerimos a criação de uma nova categoria na literatura sobre participação institucional - "Conselho Consultivo".

Palavras-chave: administração pública; democracia deliberativa; instituições participativas; conselhos; participação social.

\section{Consultative participation in Brazil: the case of the São Paulo Municipal Advisory Board}

This article analyzed the São Paulo Municipal Advisory Board, an innovative channel of communication between civil society and the local government's executive branch. This exploratory research is based on an intrinsic case study, aiming to understand the operation of this advisory board and how it relates to other participatory instances in Brazil. The study adopted semi-structured interviews with members of the advisory board and representatives of the local government, participant observation of meetings of the management's board, and analysis of official documents. Data were analyzed based on the theory of deliberative democracy and studies on participatory bodies. The results indicate that the São Paulo Municipal Advisory Board is partially aligned with the deliberative democracy, and strongly connected to the federal and state-level Councils of Social and Economic Development. Due to the specificities of these instances, we suggest the creation of a new category in the literature on institutional participation - "Governmental Advisory Board."

Keywords: public administration; deliberative democracy; participatory institutions; councils; social participation.

\section{Participación consultiva en Brasil: el caso del Consejo de la Ciudad de São Paulo}

Este artículo tiene como objeto analítico el Consejo de la Ciudad de São Paulo, un innovador canal de comunicación entre la sociedad civil y el Ejecutivo municipal. Esta investigación exploratoria se basa en un estudio de caso intrínseco cuyos objetivos son comprender el funcionamiento de ese consejo y relacionarlo a otras instituciones participativas en Brasil. Para ello, se realizaron entrevistas semiestructuradas con consejeros y representantes de la gestión municipal, observación participante y análisis de documentos oficiales. Los datos se analizaron a partir de la teoría sobre democracia deliberativa y de estudios sobre consejos participativos. Los resultados apuntan que el Consejo de la Ciudad de São Paulo está parcialmente alineado con el modelo deliberativo de democracia, y fuertemente con los ejemplos federal y de los estados de consejos de desarrollo social y económico. Por las especificidades de estas instancias, sugerimos la creación de una nueva categoría en la literatura sobre participación institucional: "Consejo Asesor".

Palabras clave: administración pública; democracia deliberativa; democracia participativa; consejo; participación social.

DOI: http://dx.doi.org/10.1590/0034-761220180427

Artigo recebido em 19 dez. 2018 e aceito em 03 fev. 2020.

ISSN: 1982-3134 (c) (1)

A pesquisa que originou este artigo foi financiada pela Coordenação de Aperfeiçoamento de Pessoal de Nível Superior (CAPES) - Código Financeiro 001.

[Versão traduzida] 


\section{INTRODUÇÃO}

Nas últimas décadas, a confluência das agendas de desenvolvimento e democratização colocou a participação social no centro da discussão sobre políticas públicas, baseando-se na argumentação de que as esferas participativas têm o potencial de aprimorar a democracia, melhorar a efetividade das políticas públicas e formar melhores cidadãos e governos (Cornwall \& Coelho, 2007). O amadurecimento e a expansão dessas práticas participativas em todo o mundo geraram uma extensa literatura sobre sua origem e processos de implementação (Avritzer, 2012).

Algumas dessas pesquisas indicaram os desafios relacionados às instituições participativas, apontando para a fragilidade dos mecanismos de participação (Coelho, 2014), as dificuldades de promover um envolvimento significativo dos cidadãos mais pobres e marginalizados (Coelho, 2013; Cornwall \& Coelho, 2007), a incerteza sobre a natureza democrática desses espaços (Casula, 2017) e a baixa efetividade e a consequente desmobilização em torno da participação (Crantschaninov, 2018).

Além disso, muitos autores têm apontado que a participação social pode assumir diversas formas, destacando a necessidade de se compreender as características singulares das diferentes esferas participativas (Avritzer, 2012; Bishop \& Davis, 2002) e a importância de observar seu contexto social, cultural e político (Cornwall, 2004). Nesse sentido, entendemos que a "participação é a expectativa de que cidadãos tenham voz nas escolhas relacionadas a políticas públicas" (Bishop \& Davis, 2002, p. 2, tradução nossa), podendo se manifestar em formatos institucionais variados.

A partir da década de 1980, os países latino-americanos passaram por processos de redemocratização que lhes permitiram explorar novas formas de participação cidadã. As instituições participativas da região são um fenômeno atualmente consolidado e bastante estudado (Avritzer, 2012), e o Brasil é o país que mais avançou na criação, por parte do Estado, de oportunidades para o envolvimento dos cidadãos na esfera pública (Cornwall, 2004). No entanto, a experiência do orçamento participativo ainda parece ser o mecanismo brasileiro mais conhecido nesse sentido, o que nos leva a reforçar o alerta de Avritzer (2012) para que se amplie a compreensão sobre as outras formas de participação institucionalizada que ocorrem no país.

Nesse contexto, São Paulo é um município interessante para análise. É uma das cidades mais influentes da América Latina, apresenta enormes desigualdades e é palco de interesses múltiplos, revelando conflitos em relação a seus ativos econômicos, sociais, políticos e culturais. A capacidade de seus gestores em gerenciar tais conflitos e lidar com relações assimétricas de poder é um elemento essencial na busca de inclusão social e diversidade.

Em 2013, o então prefeito Fernando Haddad (Partido dos Trabalhadores - PT), apresentou publicamente o programa de metas de seu mandato (2013-2016) ${ }^{1}$. O programa incluía iniciativas para promover a participação, a transparência e o envolvimento da sociedade na administração pública municipal. A meta $\mathrm{n}^{\circ} 113$ do programa mencionava a criação do Conselho de Desenvolvimento Econômico e Social de São Paulo, que mais tarde passou a ser chamado 'Conselho da Cidade de São Paulo' (CCSP).

A decisão de criar esse conselho foi tomada a partir do entendimento de que, em municípios grandes e complexos como São Paulo, a resolução de problemas coletivos é fragilizada se orientada apenas pela ação e interesses governamentais. Sua solução efetiva deve passar, portanto, por uma

\footnotetext{
${ }^{1}$ A Emenda n 30/2008 à Lei Orgânica do Município de São Paulo estabelece que todo prefeito recém-eleito deve, dentro de noventa dias após a sua posse, apresentar o Programa de Metas de sua administração, contendo ações estratégicas, indicadores e metas quantitativas para cada setor da Administração Pública Municipal.
} 
ampla discussão incluindo as perspectivas da sociedade civil, do governo, das empresas e de outros atores, na formulação de agenda e no estudo de alternativas.

Partindo dos pressupostos de que a) o CCSP é um canal inovador de diálogo entre a sociedade civil e o governo municipal; e b) que o CCSP difere de outras instituições participativas observadas no Brasil, esse conselho mostra-se um interessante caso a ser analisado. Ainda, corrobora a decisão de adotar o CCSP como objeto de estudo, o fato de que essa instituição ainda é pouco estudada na literatura, ou seja, é ainda relativamente desconhecida nos campos da administração pública, políticas públicas e das ciências sociais.

O presente artigo traz uma pesquisa exploratória e qualitativa com o objetivo de contribuir para o debate sobre instituições participativas no Brasil, orientando-se a partir de duas questões. Em primeiro lugar, o estudo busca esclarecer como o CCSP funcionava, assumindo que havia uma lacuna entre a prática e o discurso oficial dessa instituição participativa. A segunda questão, por sua vez, indaga como o CCSP se relaciona com outras instituições do gênero no Brasil. As duas questões são abordadas a partir de uma lente teórica fundamentada na revisão da literatura sobre os conceitos de democracia participativa e democracia deliberativa, e sobre a experiência brasileira com instituições caracterizadas pela participação, com ênfase nos conselhos participativos.

O artigo está estruturado em seis seções, além dessa introdução. A próxima seção traz uma revisão das teorias que abordam as democracias participativa e deliberativa, seguida pela apresentação de revisão da literatura sobre os conselhos participativos no Brasil. A terceira seção apresenta os procedimentos metodológicos utilizados para coleta e análise de dados. Logo após é introduzido com detalhes o conselho da cidade de São Paulo (CCSP), seguida da seção cinco que discorre sobre os resultados da pesquisa à luz das teorias sobre democracia e conselhos participativos observadas na revisão da literatura. Na sexta e última parte do artigo tecemos nossas considerações finais.

\section{DEMOCRACIA PARTICIPATIVA E DEMOCRACIA DELIBERATIVA - DESCRIÇÃO E CRÍTICAS AOS MODELOS}

A análise da relação entre governo e sociedade vem se aprimorando ao longo dos anos, e a compreensão da democracia nesse contexto se mostra bastante complexa - uma vez que o conceito, além de ter se transformado inúmeras vezes desde sua origem até os dias atuais, é caracterizado pela polissemia. De acordo com Nobre (2004), diversos modelos de democracia coexistem, sendo que os mais influentes no debate contemporâneo têm sido o modelo elitista (ou schumpeteriano), o pluralista, o legal, o participativo e o deliberativo. Para os propósitos do presente estudo, os três primeiros modelos, que defendem o estado mínimo e/ou a representação como princípios políticos, não serão abordados.

Nossa reflexão reconhece o debate referente à crise de instituições representativas - um tema central na teoria democrática contemporânea -, incluindo a discussão sobre o papel dos partidos políticos, que não estão mais em condição de expressar a diversidade da sociedade atual (Vizeu \& Bin, 2008; Fleury, 2006). Wampler (2010) complementa a questão, observando que a democracia representativa demonstra não responder mais a necessidade de estabelecer um bom relacionamento entre governo e sociedade, sendo a democracia participativa, portanto, a alternativa para essa função.

Os modelos participativo e deliberativo fazem uma crítica à representação política (Nobre, 2004), defendendo a participação direta dos cidadãos nos processos de tomada de decisão sobre questões coletivas. O modelo participativo está ligado aos movimentos de contestação da década de 1960, 
sendo seus principais autores Carole Pateman, Nikos Poulantzas e C. B. Macpherson. Ele se baseia no entendimento de que o capitalismo cristaliza desigualdades materiais e políticas, cuja superação se dá justamente pela ampliação da participação cidadã na governança pública.

O modelo deliberativo é geralmente organizado em torno da visão de que o exercício do poder político coletivo se baseia na argumentação pública e racional entre pares. Portanto, os processos democráticos são orientados pela discussão do bem público e valorizam argumentos, dispensando emoções. É uma teoria explicitamente normativa da democracia, baseada em argumentação racional e respeito por procedimentos imparciais de deliberação. Entre os autores paradigmáticos desse modelo estão Jurgen Habermas, Bernard Manin e Joshua Cohen.

Embora reconheçam as importantes inovações trazidas pelos modelos participativo e deliberativo, pesquisas recentes problematizam essas teorias. Iris Young (2001), por exemplo, identificou dois problemas com o modelo deliberativo. Para a autora, em primeiro lugar, o modelo restringe a discussão democrática a uma argumentação crítica, o que resulta em uma tendência a silenciar ou desvalorizar certas pessoas ou grupos. Em segundo lugar, há uma suposição errônea de que a discussão entre as partes deve necessariamente buscar um elemento comum de entendimento. Da mesma forma, Coelho (2013) discorda da noção de que arenas deliberativas devem ser isoladas de paixões políticas e sugere que a participação de atores sociais mobilizados contribui para o aumento da efetividade desses fóruns.

Além disso, Teixeira, Souza, e Lima (2012) observaram que, mesmo quando se deseja promover a troca de ideias, se não há garantia de diversidade representativa, não haverá troca efetiva. Eles se baseiam no trabalho de Young (2006), que assume que a inclusão é uma forma de qualificar a representação nos espaços participativos, uma vez que as perspectivas sociais seriam representadas ali, e são entendidas como experiências que os indivíduos têm porque fazem parte de um certo grupo.

Além disso, considerando que os espaços participativos acabam envolvendo elementos de representação, Céli Jardim Pinto coloca a seguinte questão: “Até que ponto a substituição da representação pela participação como forma de solucionar os problemas da democracia representativa não incorre nos mesmos limites delineados por esta, sem que, no entanto, se possa manter suas salvaguardas?" (2004, p. 97). A autora, bem como outros pesquisadores, observa que uma das questões mais calorosamente debatidas em relação a participação atualmente é a dicotomia entre democracia e inclusão, porque sociedades com alta desigualdade demonstram ter problemas significativos em relação à inclusão dos cidadãos mais pobres e marginalizados (Cornwall \& Coelho, 2007).

Em suma, modelos participativos e deliberativos surgiram como tentativas de minimizar os problemas encontrados com a representação. Apesar de sua recente expansão e avanços, sua implementação não é neutra e os modelos enfrentam cada qual seus específicos dilemas.

\section{CONSELHOS PARTICIPATIVOS NO BRASIL}

Estudos apontam a existência de uma grande variedade de conselhos no Brasil. Para Szwako (2012), as instituições participativas datam de meados dos anos 50, abrangendo comunidades eclesiais de base, clubes de mães e associações de moradores. A década de 1980 viu surgir no Brasil os conselhos comunitários e populares (Souto \& Paz, 2012), com arranjos organizacionais que incluíram as populações em maior vulnerabilidade social e conectando fortemente problemas locais com reivindicações por direitos.

Essas articulações foram importantes para o processo de redemocratização brasileiro, que resultou na elaboração de uma nova Constituição, em 1988. Nela estão estabelecidos espaços participativos 
institucionalizados, onde o Estado e a sociedade ficaram responsáveis pela formulação, execução e controle de políticas públicas (Szwako, 2012) ${ }^{2}$.

Além disso, o país também testemunhou a experiência dos conselhos corporativos, caracterizados "como mecanismos de confrontação dos interesses e de negociação de consensos entre atores socialmente constituídos" (Fleury, 2006, p. 6). Essas experiências coletivas de concertação podem agregar diferentes interesses e minimizar conflitos e problemas de governança, ganhando força em um cenário de autoridades governamentais desacreditadas.

A partir da década de 1930, no período do Estado Novo, o modelo nacional desenvolvimentista liderado por um governo autoritário gerou um tipo de relacionamento Estado-sociedade caracterizado, de acordo com O'Donnell (1976), como bifrontal. Nessa dinâmica, ao mesmo tempo em que o Estado subordina a frágil sociedade civil, estabelecendo instituições estatais com a finalidade de organizar os interesses sociais, ele também é 'privatizado', no sentido de estar a serviço de uma elite econômica. Em 1944, foi criado o Conselho Nacional de Política Industrial e Comercial, reunindo gestores públicos e a burocracia econômica do governo com associações empresariais e comerciais. A formação de conselhos do gênero pode ser considerada uma tendência também seguida no segundo governo de Getúlio Vargas, que fundou o Conselho Nacional de Economia, e no governo de Juscelino Kubitscheck, com seus Grupos Executivos.

Já mais recentemente, em 1991, foram introduzidas no Brasil as Câmaras Setoriais. Essas instituições também representam formas de negociação entre a iniciativa privada e a elite governamental, embora sejam diferentes uma vez que reconhecem as organizações de trabalhadores como atores importantes nas discussões, formando assim um desenho tripartite.

Em 2003, durante a administração do Presidente Luiz Inácio Lula da Silva (2003-2010) foi estabelecido o Conselho de Desenvolvimento Econômico e Social (CDES). O CDES se fundamenta na relação mais estreita entre Estado e sociedade e, segundo Fleury (2006, p. 11), gera "um novo espaço institucionalizado e plural no qual se encontram diferentes atores políticos e o governo, possibilitando um processo de concertação social e novas bases para garantir a governabilidade". Para a autora, o CDES foi o exemplo mais recente de "democracia concertada" ocorrido no Brasil. Ela o vê como uma inovação social porque, em uma sociedade marcada por desigualdades, abriu-se um espaço de discussão compartilhado por atores sociais que anteriormente não interagiam, demonstrando uma expansão da esfera pública. É importante observar que, diferente dos mecanismos corporativos, o CDES não objetiva criar consenso entre as partes econômicas interessadas, mas reunir uma ampla composição de atores relevantes para discutir políticas específicas e o desenvolvimento econômico e social do país.

Vizeu e Bin (2008) corroboram a visão de Fleury sobre o papel consultivo e não deliberativo do $\mathrm{CDES}$, problematizando alguns aspectos de seu funcionamento. Para os autores, o conselho enfrenta desafios similares aos identificados na literatura sobre instituições participativas, como a dificuldade de reconhecer a igualdade política de todos os participantes e a baixa efetividade de suas decisões.

Ao analisar o Conselho de Desenvolvimento Econômico e Social do Estado do Rio Grande do Sul, Santos (2016) apontou similaridades entre o conselho estudado e o CDES, particularmente em relação a características e desafios na busca de efetividade. Entre as conquistas do Conselho do Rio Grande do Sul, estão o reconhecimento de sua contribuição para a maior transparência e acesso à informação,

\footnotetext{
${ }^{2}$ Segundo Teixeira et al. (2012), os conselhos populares foram os embriões dos conselhos de políticas públicas, e sua expansão ocorreu em grande parte devido a novos requisitos legais para a distribuição de recursos financeiros.
} 
bem como para a melhoria de políticas públicas. Entretanto, os critérios adotados na composição e a pouca capacidade de influenciar a agenda do órgão reduziram o seu potencial deliberativo. A pesquisa de Santos (2016) também revelou que o conselho depende em grande parte da vontade política do governador, identificando incertezas sobre a continuidade de suas atividades em governos subsequentes.

Em síntese, essa seção revela que tipos muito diferentes de arranjos institucionais foram denominados como 'conselhos', incluindo grupos populares (mais próximos do tecido social e relacionados à autonomia popular), estruturas vinculadas a políticas públicas e até agremiações corporativas reunindo representantes de empresas e trabalhadores junto ao governo para concertação e negociação. Também adotaram a denominação os Conselhos de Desenvolvimento Econômico e Social, fóruns envolvendo o governo federal ou estadual e diferentes atores políticos para promover o desenvolvimento e a governabilidade. Esses agrupamentos têm formatos e propósitos muito diferentes. Para melhor compreensão das experiencias mais recentes de conselhos participativos no Brasil, na próxima seção descreveremos suas principais características.

\subsection{TIPOLOGIA DOS ATUAIS CONSELHOS PARTICIPATIVOS NO BRASIL}

Segundo Avritzer (2012), o novo constitucionalismo brasileiro gerou três tipos de desenhos participativos diferentes: desenho de baixo para cima, desenho de partilha e desenho institucional de ratificação. O presente estudo se concentra no segundo tipo, desenho de partilha do poder, que diz respeito explicitamente ao que ocorre no caso dos conselhos. Cohn (2011) explica a dupla função dessas instâncias, ou seja, a) permitir que as demandas da sociedade sejam ouvidas pelo Estado e, consequentemente, b) alinhar o desenho das políticas públicas às necessidades da população.

De acordo com Teixeira et al. (2012, p. 51), as instituições participativas funcionam de diferentes maneiras, variando "de acordo com o contexto de institucionalização, a forma de organização social, a definição do papel e dos objetivos do colegiado e a delimitação da competência e das atribuições do conselho". Para os autores, um conselho pode ser definido, geralmente, como um espaço de caráter deliberativo ou consultivo, com certa permanência ao longo do tempo. Ainda, apresentam uma categorização bastante útil dos vários papéis dos conselhos (Quadro 1).

\section{QUADRO 1 ATRIBUIÇÕES PREDOMINANTES E PÚBLICOS ALVOS POR TIPO DE CONSELHO}

\begin{tabular}{lll} 
Tipo de conselho & \multicolumn{1}{c}{ Atribuições predominantes } & \multicolumn{1}{c}{ Públicos prioritariamente convocados } \\
Políticas públicas & $\begin{array}{l}\text { - Apontar diretrizes e prioridades } \\
\text { - Normatizar procedimentos }\end{array}$ & $\begin{array}{l}\text { - "Especialistas" } \\
\text { - Interesses em conflito (por exemplo, entre capital e } \\
\text { trabalho), e o Estado parece ter a função de mediador. }\end{array}$ \\
Direitos & $\begin{array}{l}\text { - Coordenar, monitorar e avaliar as políticas, } \\
\text { promover a participação e orientar diferentes } \\
\text { públicos. }\end{array}$ & $\begin{array}{l}\text { - Marginalizados do sistema político } \\
\text { (movimentos populares e movimentos identitários). }\end{array}$ \\
& $\begin{array}{l}\text { - Aprovar planos de contas e de relatórios de } \\
\text { Fundos }\end{array}$ & $\begin{array}{l}\text { - Interesses em conflito (por exemplo, entre capital } \\
\text { ge trabalho), e o Estado parece ter a função de }\end{array}$ \\
& $\begin{array}{l}\text { - Julgar processos e concessão de benefícios a } \\
\text { determinadas organizações. }\end{array}$ & \\
\hline
\end{tabular}

Fonte: Teixeira et al. (2012, pp. 58-59). 
Ao separar os conselhos participativos de acordo com suas atribuições predominantes e público prioritário, os autores permitem comparações entre eles, fornecendo possibilidades analíticas interessantes para esta pesquisa e o estudo do CCSP. Também é importante mencionar que essas revisões recentes nos conselhos participativos não incluem conselhos corporativos ou de concertação, como CDES ou CCSP.

\section{PROCEDIMENTOS METODOLÓGICOS}

A abordagem metodológica foi baseada na lógica do estudo de caso intrínseco (Stake, 2008), uma técnica escolhida quando se deseja entender melhor o caso específico em virtude de um interesse intrínseco por ele, sendo que o objetivo da abordagem não é entender algum fenômeno genérico ou construto abstrato, nem construção de teoria - embora isso não impeça o pesquisador de fazê-lo. Essa escolha metodológica é ancorada em tradições não positivistas e, por isso, a estrutura do artigo se distancia das crenças básicas do paradigma positivista, como a verificação de hipóteses e especificação de variáveis independentes e dependentes.

O estudo de caso foi conduzido com a utilização de três técnicas associadas a essa tradição de pesquisa, a análise documental, a observação participante e as entrevistas. Quando comparada com estudos quantitativos, a pesquisa qualitativa apresenta um maior grau de subjetividade nos procedimentos, seleção, gerenciamento e análise de dados - conforme descrito por Beltrão e Nogueira (2011) - e exige grande clareza e transparência ao relatar os procedimentos adotados pelas pesquisadoras, conforme detalhado abaixo.

A coleta de dados foi realizada em duas etapas, com objetivos diferentes. A análise documental foi adotada como estratégia inicial de pesquisa, visando compreender como os documentos governamentais descrevem a instituição e seu trabalho. Foi realizada uma revisão dos materiais disponíveis publicamente como o decreto de criação do Conselho da Cidade de São Paulo (CCSP) e seu site institucional. No entanto, diferentemente de outros conselhos, o site do CCSP não dava acesso público à ata de todas as suas reuniões e aquelas que estavam disponíveis online ficaram inacessíveis a partir de 2017, quando João Dória (Partido da Social Democracia Brasileira - PSDB) assumiu a Prefeitura de São Paulo.

Os entrevistados forneceram o regimento interno do CCSP para análise. O documento detalhava as metas e regras de funcionamento do conselho, sua estrutura e composição, incluindo os grupos de trabalho, a plenária e o comitê gestor. A técnica de observação participante foi adotada com a presença das pesquisadoras em duas reuniões do comitê gestor do CCSP em outubro e novembro de 2015. As pesquisadoras foram apresentadas aos membros do conselho no início das reuniões e os encontros foram registrados em diários de campo, posteriormente convertidos em escritos mais elaborados.

Além disso, foram conduzidas cinco entrevistas com conselheiros do CCSP e gestores públicos do município que haviam trabalhado no Conselho, realizadas entre outubro e novembro de 2015 (uma das cinco pessoas entrevistadas foi consultada novamente em outubro de 2019). Os entrevistados foram escolhidos intencionalmente, considerando o setor em que trabalhavam e a oportunidade de acesso a eles por parte das pesquisadoras. Para preservar suas identidades, os entrevistados foram designados por letras (Quadro 2). As entrevistas seguiram o roteiro semiestruturado disponível no Anexo 1, duraram entre quarenta minutos e uma hora e foram totalmente gravadas, transcritas e codificadas, facilitando a subsequente análise. 


\section{QUADRO 2 IDENTIFICAÇÃO DOS ENTREVISTADOS POR INSTITUIÇÃO E PAPEL NO CCSP}

\begin{tabular}{|c|c|c|c|}
\hline Entrevistados & Instituição* & Papel & Data da entrevista \\
\hline A & $\begin{array}{l}\text { Secretaria Municipal de } \\
\text { Relações Governamentais }\end{array}$ & $\begin{array}{l}\text { Formulação e implementação } \\
\text { do CCSP }\end{array}$ & $\begin{array}{l}\text { outubro/2015 } \\
\text { outubro/2019 }\end{array}$ \\
\hline B & $\begin{array}{l}\text { Conselho da Cidade de São } \\
\text { Paulo (CCSP) }\end{array}$ & $\begin{array}{l}\text { Conselheiro(a) e Professor(a) } \\
\text { universitário(a) }\end{array}$ & novembro/2015 \\
\hline C & $\begin{array}{l}\text { Secretaria Municipal de } \\
\text { Relações Governamentais }\end{array}$ & $\begin{array}{l}\text { Formulação e implementação } \\
\text { do CCSP }\end{array}$ & novembro/2015 \\
\hline D & $\begin{array}{l}\text { Secretaria Municipal de } \\
\text { Relações Governamentais }\end{array}$ & Coordenação do CCSP & novembro/2015 \\
\hline$E$ & $\begin{array}{l}\text { Conselho da Cidade de São } \\
\text { Paulo (CCSP) }\end{array}$ & $\begin{array}{l}\text { Conselheiro(a) e diretor(a) de } \\
\text { organização sem fins lucrativos }\end{array}$ & novembro/2015 \\
\hline
\end{tabular}

Fonte: Elaborado pelas autoras.

*Os entrevistados vinculados com a administração municipal não estavam necessariamente atuando no CCSP no período da pesquisa, mas foram selecionados em virtude de seu histórico de contribuição ao conselho.

A codificação foi feita a partir de uma estratégia simplificada, facilitando a análise dos dados. Os códigos funcionam como rótulos que atribuem significado às informações descritivas ou inferenciais compiladas. Eles podem ser usados para recuperar e categorizar blocos de dados semelhantes, permitindo que se "encontre, retire e agrupe rapidamente os segmentos relacionados a uma pergunta de pesquisa específica (...)" (Miles \& Huberman, 1994, p. 57, tradução nossa). O estudo utilizou simultaneamente duas abordagens de codificação de primeiro ciclo: uma descritiva e outra de avaliação. A abordagem descritiva atribui código aos dados, resumindo em uma palavra ou frase curta o tópico básico de uma passagem de dados qualitativos. A codificação de avaliação aplica códigos que atribuem julgamentos sobre o mérito, valor ou importância dos programas ou políticas públicas. Dito isto, a análise dos dados foi baseada nos seguintes códigos: papéis e atribuições, composição, seleção de membros, conteúdo das reuniões, consultivo x deliberativo, CCSP x CDES, avaliação e dinâmica de funcionamento.

\section{CONSELHO DA CIDADE DE SÃO PAULO}

O Conselho da Cidade de São Paulo será apresentado de forma estruturada nas seguintes subseções: papéis e atribuições, membros do conselho, estrutura institucional - inspirando-se nos critérios analíticos usados por Teixeira et al. (2012) - e a avaliação do CCSP, a partir da perspectiva dos entrevistados. 


\subsection{PAPÉIS E ATRIBUIÇÕES DO CONSELHO DA CIDADE DE SÃO PAULO: POR QUE ELE EXISTE?}

De acordo com o Decreto no 53.796 de 2013, que instituiu o Conselho da Cidade de São Paulo, e com seu regimento interno, o CCSP é um "órgão de assessoramento imediato ao Prefeito na implementação do desenvolvimento econômico, social e ambientalmente sustentável da Cidade de São Paulo". Com o objetivo de promover participação social e cidadã como um método de governo, o decreto estabeleceu as seguintes funções para o CCSP (Lei n ${ }^{\circ} 53.796 / 2013$, Art. 2º):

I - Assessorar o Prefeito na formulação de políticas, indicações normativas e ações governamentais específicas;

II - Debater, orientar e apreciar propostas de políticas públicas e reformas estruturais submetidas pelo Prefeito;

III - Sugerir, propor, elaborar e apresentar ao Prefeito relatórios, estudos, projetos, acordos e pareceres, reunindo as contribuições dos diversos setores da sociedade civil;

IV - Organizar, promover e acompanhar debates acerca das medidas necessárias para a promoção do desenvolvimento econômico, social e ambiental da Cidade.

Quando observada à luz das teorias sobre democracia participativa, a definição formal dos papéis do CCSP parece ambígua, uma vez que o conselho tem por objetivo promover a participação social como método de governo (com maior envolvimento dos cidadãos nos processos de tomada de decisão), mas é descrito como um órgão de assessoramento do prefeito (o que lhe confere um caráter consultivo).

As entrevistas, por sua vez, sugerem que o CCSP se distancia dos conselhos corporativos e de seu formato voltado à negociação. Portanto, o CCSP poderia ser visto como um espaço deliberativo, onde os participantes conduzem discussões racionais focadas no bem público, auxiliando o mandatário municipal na tomada de decisões. O CCSP foi frequentemente descrito nas entrevistas como um espaço de argumentação, debate, troca de opiniões e perspectivas, e não como uma instância de decisão.

No entanto, essa definição preliminar pode ser refinada quando considerados outros dados obtidos pelas entrevistas. De acordo com o entrevistado A, as funções desempenhadas pelo CCSP eram: (1) servir como medidor ou termômetro das propostas do poder executivo; (2) discutir políticas importantes para a cidade; e (3) ser um espaço de apoio às ações governamentais. Já o entrevistado B argumenta que tem dúvidas sobre o papel consultivo do CCSP, lembrando ocasiões em que o prefeito não considerou as recomendações do conselho.

O entrevistado C, por sua vez, descreve o CCSP como um espaço para o diálogo e a apresentação de diferentes visões da sociedade, no qual "o jogo é aberto" (Entrevistado C). Além disso, identifica uma inovação: o CCSP é visto como um local de prestação de contas do administrador público para o cidadão. Outro entrevistado acrescenta que, além de aconselhar, o órgão pode proativamente apresentar propostas. Por fim, vale ressaltar que as entrevistas também indicaram os limites deliberativos do conselho: seus membros são livres para debater e sugerir, mas a palavra final pertence ao prefeito, que escuta e decide. 


\subsection{MEMBROS DO CONSELHO DA CIDADE DE SÃO PAULO: QUEM SÃO OS PARTICIPANTES?}

Os membros do CCSP não são eleitos pela população, mas nomeados pelo chefe do Poder Executivo Municipal. De acordo com seu regimento interno (Art. 3. III), o conselho é composto por até 90 cidadãos de "notória representatividade e reconhecida atuação social, econômica e ambiental, que possam contribuir para o desenvolvimento sustentável da Cidade com sua experiência e conhecimento".

Esta descrição da seleção dos conselheiros sugere que o prefeito pode lançar mão de considerável discricionariedade. Um dos entrevistados (D), porém, afirma que o mandatário parece não se beneficiar desse poder, em suas palavras, "há possibilidade de indicação, mas, na verdade, o prefeito escolhe com base em uma lista e várias pessoas contribuem". Mesmo assim, o mesmo entrevistado observa que os critérios de seleção não são claros:

Não tem uma regra estabelecida, a gente define [a seleção dos conselheiros] com base em critérios soltos. Não tem um critério pré-definido. Nós, quando eu falo, na verdade, é o Prefeito. Mas, como tudo na Prefeitura, tem uma triagem. (...) Na real, o que acontece mesmo é que é extremamente subjetivo (Entrevistado D).

A subjetividade na seleção de membros do conselho aparece também em outras entrevistas, como, por exemplo, na fala do entrevistado A: "o Prefeito escolhe os setores com quem quer dialogar. Mas Haddad é republicano e não formou um Conselho de 'amigos"' (Entrevistado A). O CCSP é composto por pessoas que representam a visão de segmentos da sociedade "que têm uma visão mais à esquerda" (Entrevistado D) ou que estão abertos ao diálogo. De fato, fazem parte do conselho pessoas de partidos da oposição como o Partido da Social Democracia Brasileira (PSDB) e o Partido do Movimento Democrático Brasileiro (PMDB).

De acordo com o site oficial do $\mathrm{CCSP}^{3}$, há um esforço para que estejam representados os diferentes setores da sociedade, como "movimentos sociais, empresariado, sindicalistas, intelectuais, imprensa, religiões, educadores, pesquisadores, cientistas, minorias, poderes constituídos etc.". No entanto, existem diferenças entre os perfis dos membros quando se compara as diversas composições do CCSP (os conselheiros são eleitos por dois anos: o primeiro mandato foi em 2013/2015 e o segundo em 2015/2017). A principal mudança foi a ausência, na segunda composição, de membros do sistema judiciário e de instituições religiosas (Gráfico 1.) Segundo o entrevistado A, a decisão de descontinuar a participação desses conselheiros na segunda composição do CCSP foi tomada em uma reunião do comitê gestor, com base no entendimento compartilhado de que os representantes desses segmentos não haviam se engajado adequadamente nas atividades do conselho.

\footnotetext{
${ }^{3} \mathrm{O}$ site http://conselhodacidade.prefeitura.sp.gov.br/ estava em funcionamento durante a realização da pesquisa, mas saiu do ar depois da posse do prefeito João Dória (PSDB), em 2017.
} 


\section{GRÁFICO 1 COMPOSIÇÃO DO CONSELHO DA CIDADE DE SÃO PAULO: 2013 E 2015}

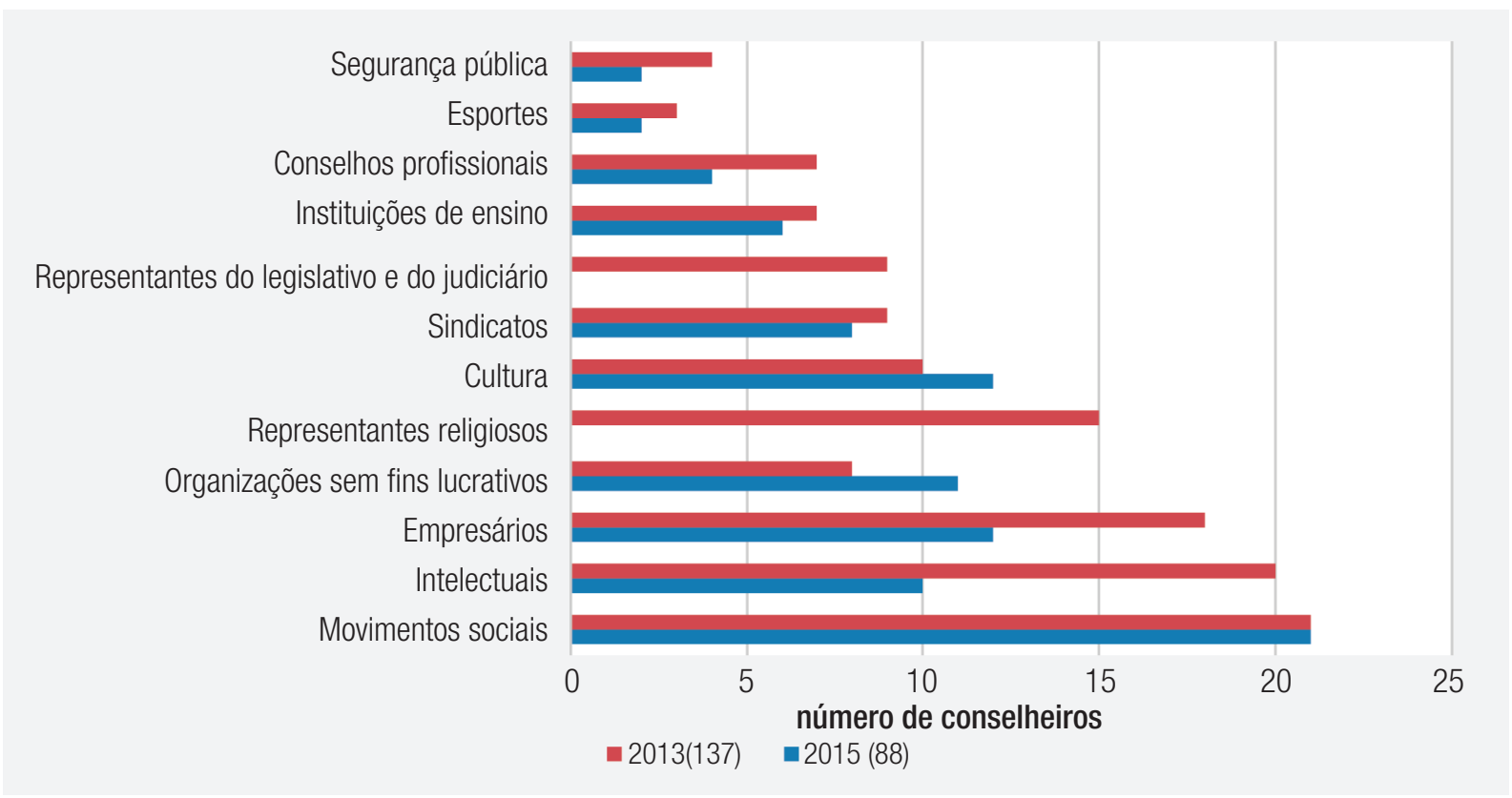

Fonte: Elaborado pelas autoras, com base em dados oferecidos pelos entrevistados.

O gráfico também revela uma diminuição no número de conselheiros. Em sua primeira composição, o CCSP contava com 137 membros provenientes da sociedade civil, administração pública municipal e outras instituições governamentais como o Ministério Público e Polícia Militar. Na segunda composição o número de membros foi reduzido a 90.

Portanto, o fato da seleção de conselheiros ser uma prerrogativa exclusiva do prefeito, com base na 'notória representatividade', enseja algumas questões. Primeiro, como observa Pinto (2004), o processo de seleção pode potencializar a dicotomia entre democracia e inclusão, uma vez que uma parte significativa da população permanece alijada desses espaços. Em segundo lugar, não havia evidência clara de responsabilidade dos conselheiros perante os grupos que supostamente representavam, levantando questões sobre até que ponto essa estratégia de participação mantém os mesmos problemas da democracia representativa, sem garantir suas salvaguardas (através de eleições por exemplo).

\subsection{A institucionalidade do CCSP}

A estrutura do CCSP integrava a Secretaria Municipal de Relações Governamentais (SMRG), cujo objetivo era coordenar politicamente o poder executivo e seu relacionamento com o poder legislativo, a sociedade civil e outras instituições. De 2013 a 2015, a SMRG trocou de secretário quatro vezes e o conselho teve dois coordenadores diferentes. De acordo com o entrevistado E, essas mudanças têm consequências negativas, pois "a memória social se perde". Essa instabilidade pode, de fato, ter influenciado o trabalho do conselho, uma vez que o sucesso da gestão participativa depende do compromisso do gestor público (Wampler, 2010).

Em relação à sua estrutura institucional, o CCSP possuía uma secretaria executiva responsável por sua administração, operacionalizada por servidores públicos da própria SMRG, ou seja, subordinados 
ao secretário municipal da pasta. Além disso, as instâncias do CCSP se resumiam a reuniões plenárias, comitê gestor e grupos de trabalho.

As reuniões plenárias eram regulares e extraordinárias, envolvendo todos os membros do conselho, o prefeito e alguns secretários municipais. De acordo com o regimento interno, a plenária ocorre ordinariamente quatro vezes por ano, por convocação do prefeito. Podem ocorrer plenárias extraordinárias sempre que o prefeito optar por consultar os conselheiros sobre assuntos relevantes (ou por solicitação de ao menos 30\% dos conselheiros). Alterações na agenda de reuniões regulares, bem como convocações para plenárias extraordinárias, devem ser informadas com 48 horas de antecedência.

O comitê gestor é uma instância interna com o objetivo de discutir assuntos relevantes para o funcionamento do conselho, bem como propor e discutir a agenda e questões importantes, auxiliando o trabalho da secretaria executiva. É composto por 10\% dos conselheiros, eleitos entre os membros do colegiado para um mandato de um ano. Os grupos de trabalho são criados a partir da demanda de pelo menos 15 conselheiros. Em 2015, dois grupos de trabalho estavam ativos: Mobilidade urbana e Formação para a cidadania: direitos humanos e diversidade.

Embora os mecanismos e espaços do CCSP sejam formalmente organizados, as entrevistas indicaram que sua dinâmica real de funcionamento era diversa. Os entrevistados apontaram a existência de certa ambiguidade ou falta de entendimento sobre o papel dos conselheiros, o que potencialmente contribuiu para a baixa capacidade do conselho em influenciar o processo de tomada de decisão. Durante uma das oportunidades da aplicação da observação participante, as pesquisadoras coletaram a fala de um dos conselheiros apontando problemas de comunicação e falta de clareza sobre seu papel no relacionamento com o prefeito e com a secretaria executiva.

Além disso, os dados coletados nas entrevistas e na observação participante indicaram que os temas abordados nas reuniões plenárias do CCSP eram temas 'urgentes' em São Paulo, como mobilidade urbana, plano diretor, crise hídrica, creches, entre outros. Os dados também revelam que não há evidência clara de que o CCSP teve influência significativa nas políticas públicas municipais, embora tenha incidido nas decisões a respeito do programa municipal denominado 'Ruas Abertas', mais precisamente o caso do 'Paulista Aberta'. O programa envolvia uma questão controversa, e a posição favorável do CCSP “deu força para virar um projeto do governo" (Entrevistado A).

Já no caso da mobilidade urbana, as entrevistas mostraram o descompasso entre a opinião do conselho e a do prefeito, por exemplo, na questão do aumento de tarifas do transporte público. O CCSP se pronunciou contrário ao aumento dos valores durante as manifestações populares ocorridas em junho de 2013 na cidade e em todo o país - marcando um importante momento na história política brasileira. O prefeito Fernando Haddad, no entanto, optou por seguir com o aumento da tarifa, rejeitando a recomendação do conselho, mudando de ideia somente algum tempo depois, acompanhando uma decisão do governador de São Paulo, Geraldo Alckmin, de manter as tarifas do metrô inalteradas.

Dialogando com o estudo de Lima et al. (2014), argumentamos que o CCSP teve uma reduzida institucionalização. Segundo os autores, pode-se analisar a institucionalização de conselhos a partir de três dimensões. A primeira é o reconhecimento formal do conselho, por parte do Estado, como uma instância que integra o processo decisório. Trata-se de um reconhecimento legal e inclui a vinculação do conselho a outras políticas e sistemas participativos (em âmbito nacional, por exemplo). No caso do CCSP, houve um decreto instituindo o órgão (Decreto 53.796/2013) que, no entanto, não deu ao conselho um caráter deliberativo, além de permitir que a estrutura fosse destituída pelas autoridades a qualquer momento, uma vez que não foi vinculada a outras políticas de Estado. 
A segunda dimensão diz respeito à disponibilidade de recursos materiais, organizacionais e técnicos necessários ao trabalho do conselho. Lima et al. (2014) destacam entre esses recursos a disponibilidade de uma secretaria executiva e a previsão de grupos de trabalho. O CCSP demonstrou certa institucionalização nesse aspecto, contando com uma secretaria e a faculdade de atuar por meio de grupos temáticos. Finalmente, a terceira dimensão sugerida pelos autores é a do aprendizado acumulado, onde o tempo de funcionamento e a experiência adquirida refletem uma maior institucionalização. Nesse sentido, a trajetória do CCSP não demonstrou aprendizado acumulado uma vez que funcionou somente durante a administração do prefeito Fernando Haddad.

\subsection{Avaliação do Conselho da Cidade de São Paulo}

Quando solicitados a avaliar o CCSP, os entrevistados deram respostas bastante diversas (Quadro 3). Os aspectos positivos incluíram o reconhecimento da instituição como um novo canal de participação, onde diferentes perspectivas alcançam visibilidade e o fato de o prefeito poder se aproximar dos cidadãos e expor seus planos a diferentes segmentos representados. Por outro lado, a menção a pontos negativos e desafios foi heterogênea, refletindo diferenças claras nas opiniões dos participantes. Os entrevistados que fazem parte da administração municipal mencionaram problemas relacionados à falta de institucionalização do CCSP, o que gerou dependência excessiva do prefeito (e de seu interesse na manutenção de tal instância), e riscos para sua sustentabilidade a longo prazo. Os membros do conselho, por sua vez, demonstravam preocupação com as operações diárias do conselho, como a capacidade dos conselheiros de ouvir outros pontos de vista e a mudança frequente de secretários municipais na gestão da SMRG, afetando o desempenho do CCSP.

Além disso, um gestor público mencionou uma preocupação diferente, evidenciando a complexidade de lidar com a contribuição oferecida por instituições participativas no dia-a-dia da administração pública: a falta de consenso, dentro do governo, sobre o papel do CCSP. O entrevistado C mencionou que a secretaria executiva do CCSP foi acusada por outros departamentos do executivo municipal de "expor" o prefeito durante os protestos de junho de 2013.

\section{QUADRO 3 AVALIAÇÃO GERAL DO CONSELHO DA CIDADE}

\begin{tabular}{|c|c|c|c|}
\hline & Aspectos positivos & Aspectos negativos & Desafios \\
\hline Governo & $\begin{array}{l}\text { - Conselho é um canal de participação, ao mesmo } \\
\text { tempo que serve como um termômetro para } \\
\text { que o governo possa avaliar a aderência de uma } \\
\text { determinada proposta. } \\
\text { - } 0 \text { prefeito apresenta sua visão sobre a cidade para } \\
\text { diferentes grupos sociais em um único espaço. } \\
\text { - Possibilita a articulação e o fortalecimento da } \\
\text { sociedade civil organizada. } \\
\text { - Diversidade de representação em um espaço } \\
\text { público. }\end{array}$ & $\begin{array}{l}\text { - Falta de consenso interno } \\
\text { no governo sobre o papel } \\
\text { do conselho. } \\
\text { - Não é um espaço } \\
\text { plenamente } \\
\text { institucionalizado, e não há } \\
\text { garantia de continuidade } \\
\text { em um próximo governo. }\end{array}$ & $\begin{array}{l}\text { - Funcionamento } \\
\text { característico da } \\
\text { máquina pública (sujeito } \\
\text { ao resultado de eleições). }\end{array}$ \\
\hline
\end{tabular}




\begin{tabular}{|c|c|c|c|}
\hline & Aspectos positivos & Aspectos negativos & Desafios \\
\hline Conselheiros & $\begin{array}{l}\text { - Possibilidade de ouvir diferentes pontos de vista. } \\
\text { - Espaço de compartilhamento de ideias que } \\
\text { antes não eram disseminadas. }\end{array}$ & $\begin{array}{l}\text { - Mudanças políticas } \\
\text { afetam negativamente a } \\
\text { continuidade do trabalho. }\end{array}$ & $\begin{array}{l}\text { - A influência dos } \\
\text { conselheiros depende de } \\
\text { seu potencial de ouvir e } \\
\text { persuadir. }\end{array}$ \\
\hline
\end{tabular}

Fonte: Elaborado pelas autoras, baseado nas entrevistas.

\section{CONSTRUINDO PONTES ENTRE TEORIA E PRÁTICA}

Nessa seção, retoma-se a literatura na intenção de estabelecer conexões entre ela e o debate que emerge do caso estudado. Primeiro, em relação aos modelos de democracia, a análise de caso dá evidências de que o CCSP possui características que remetem ao modelo deliberativo. No entanto, $o$ conselho está distante de se caracterizar como uma instância de deliberação na forma ideal. Segundo a teoria deliberativa os participantes de estruturas que seguem esse modelo são considerados iguais entre si, valorizam a argumentação racional e podem mudar de opinião. No caso dos membros do CCSP, eles tendem a defender uma posição consolidada e não há busca coletiva de consenso (o conselho foi apresentado por vários entrevistados como um espaço argumentativo, onde diferentes perspectivas e opiniões são disseminadas). Como resultado dessa dinâmica, ideias pouco conhecidas se tornam mais visíveis e perspectivas diferentes florescem em uma mesma arena.

Em segundo lugar, entre os tipos de conselho observados no Brasil, o CCSP parece ter mais semelhança com o CDES do que com outros mecanismos de participação. O CCSP não foca na construção de consenso entre grupos organizados, não aborda uma política ou tema público específico, não toma decisões de alocação de recursos ou aprova propostas do governo e não administra fundos públicos. Suas principais características são semelhantes às encontradas no estudo de Fleury (2006) sobre o CDES: em um município ou país marcado por desigualdades e com problemas sociais e urbanos complexos, essa estrutura apresenta diferentes atores que normalmente não interagem no mesmo espaço de diálogo, contribuindo para ampliar a esfera pública e as perspectivas envolvidas na discussão. As conclusões de Vizeu e Bin (2008) sobre a efetividade do CDES também ecoam no presente estudo: o CCSP parece ser um espaço de diálogo e de busca, por parte do governo, de apoio e legitimidade, mais do que um local para elaborar propostas de reformas a partir do diálogo com representantes da sociedade.

Em suma, o CCSP não recebeu nenhuma das atribuições tradicionalmente dadas a conselhos de políticas públicas, de direitos ou de fundos. O Quadro 4 mostra uma releitura do Quadro 1 apresentado anteriormente, sugerindo a criação de um novo tipo de conselho participativo, o Conselho Consultivo, fundamentado nos resultados obtidos no presente estudo e nas pesquisas sobre os Conselhos de Desenvolvimento Econômico e Social no âmbito federal (Fleury, 2006; Vizeu \& Bin, 2008) e estadual (Santos, 2016).

Finalmente, temos duas observações a serem feitas. Primeiro, a diversidade de temas abordados no CCSP pode explicar a dificuldade de se obter clareza quanto ao seu papel. Mesmo que todos os membros do conselho tenham experiência de liderança e considerável conhecimento, a variedade de tópicos abordados (qualquer tópico "urgente" em São Paulo) leva a presumir que os conselheiros frequentemente encontrarão temas com os quais não estão familiarizados. 


\section{QUADRO 4 PRINCIPAIS PAPÉIS E ATRIBUIÇÕES POR TIPO DE CONSELHO}

\begin{tabular}{|c|c|c|}
\hline Tipo de conselho & Principais papéis e atribuições & Públicos prioritários \\
\hline Políticas públicas & $\begin{array}{l}\text { - Apontar diretrizes e prioridades. } \\
\text { - Normatizar procedimentos. }\end{array}$ & $\begin{array}{l}\text { - "Especialistas". } \\
\text { - Interesses em conflito (por exemplo, entre capital } \\
\text { e trabalho), e o Estado parece ter a função de } \\
\text { mediador. }\end{array}$ \\
\hline Direitos & $\begin{array}{l}\text { - Coordenar, monitorar e avaliar as políticas, } \\
\text { promover a participação e orientar } \\
\text { diferentes públicos. }\end{array}$ & $\begin{array}{l}\text { - Marginalizados do sistema político } \\
\text { (Movimentos populares e movimentos identitários). }\end{array}$ \\
\hline Fundos & $\begin{array}{l}\text { - Aprovar planos de contas e de relatórios de } \\
\text { gestão do fundo. } \\
\text { - Julgar processos e concessão de benefícios } \\
\text { a determinadas organizações. }\end{array}$ & $\begin{array}{l}\text { - Interesses em conflito (por exemplo, entre capital } \\
\text { e trabalho), e o Estado parece ter a função de } \\
\text { mediador. }\end{array}$ \\
\hline Consultivo & $\begin{array}{l}\text { - Atuar como órgão consultivo ao chefe do } \\
\text { poder executivo. } \\
\text { - Ser um espaço de diálogo e pressão. }\end{array}$ & $\begin{array}{l}\text { - Cidadãos com representatividade notória (lideranças) } \\
\text { em diversos setores: empresas, movimentos sociais, } \\
\text { sindicatos. }\end{array}$ \\
\hline
\end{tabular}

Fonte: Elaborado pelas autoras a partir de Teixeira et al. (2012, pp. 58-59) e dos resultados da pesquisa.

Em segundo lugar, a presente pesquisa destaca os limites da participação dos conselheiros em uma instância como o CCSP. Embora os cidadãos envolvidos tenham relativa liberdade para debater e propor tópicos, expor suas perspectivas, criticar ou elogiar políticas governamentais e sugerir projetos, eles não detêm o poder de decisão, que permanece concentrado no poder executivo.

\section{CONSIDERAÇÕES FINAIS}

O Conselho da Cidade de São Paulo (CCSP) criado pelo ex-prefeito Fernando Haddad (2013-2016) é um inovador canal de comunicação entre a sociedade civil e a administração pública municipal. É importante reconhecer seu potencial de expansão da esfera pública por meio de um espaço de diálogo e participação cidadã.

Considerando a inovação proposta pelo Conselho da Cidade e a necessidade apontada por Avritzer (2012) e Bishop e Davis (2002) de ampliar a compreensão sobre as diferentes instituições participativas, esse artigo buscou responder duas perguntas de pesquisa relacionadas a) a descrição do funcionamento do CCSP, e b) a sua relação com outros conselhos participativos existentes no Brasil.

Os resultados do estudo indicam que o CCSP converge parcialmente ao modelo democrático deliberativo e, mais importante, se assemelha ao modelo dos Conselhos de Desenvolvimento Econômico e Social (CDES). No entanto, os entrevistados e a literatura revisada também problematizaram a característica deliberativa tanto no CCSP como no CDES. Por exemplo, os entrevistados destacam que os conselheiros são chamados a dar suas opiniões, mas a tomada de decisão continua sendo uma prerrogativa exclusiva do prefeito. Por esse motivo, com base em Bishop e Davis (2002), o Conselho da 
Cidade pode ser definido como um instrumento de participação na forma de consulta, reconhecendo que os governos é que seguem tomando as decisões.

Considerando os resultados desta pesquisa e de outros estudos que analisam o CDES, ficou clara a necessidade de revisar a tipologia atual das instituições participativas no Brasil. A proposta que emerge nesse estudo é a do Conselho Consultivo, uma tipologia que inclui as experiências do CCSP e dos CDES federal e estaduais, e representa espaços de diálogo e pressão que envolvem diversos representantes da sociedade e do governo, além de servirem como 'termômetros' capazes de indicar a aderência de diversos segmentos sociais a ideias e ações propostas pelo poder executivo.

É interessante notar que os conselhos que se incluem nessa nova tipologia apresentam outras características em comum. Primeiro, lidam com questões complexas e multifacetadas (desenvolvimento social e econômico ou os inúmeros tópicos considerados urgentes em uma cidade como São Paulo). Em segundo lugar, são instâncias que não pretendem criar consenso ou acordos, nem definir ou avaliar políticas ou ações governamentais. Finalmente, esse tipo de conselho constitui espaços de debate, confronto e de contato do governo com uma variedade de demandas, pontos de vista e interesses sociais. Portanto, parece razoável não criticar essas estruturas por déficit democrático, considerando que não pretendem envolver seus membros diretamente nos processos de tomada de decisões.

Outro ponto a observar é a preocupação apontada por um dos entrevistados sobre a dependência da vontade política da autoridade pública, uma inquietação que posteriormente se mostrou justificada. No início de seu mandato, em janeiro de 2017, o prefeito que sucedeu a Fernando Haddad, João Dória, extinguiu a Secretaria Municipal de Relações Governamentais, substituindo-a pela Secretaria Municipal de Privatização e Parcerias ${ }^{4}$, e interrompeu a dinâmica de trabalho então desenvolvida pelo CCSP.

Finalmente, pesquisas mais amplas que considerem a análise de um período mais longo e que observem diferentes conselhos consultivos são necessárias para dar maior consistência às conclusões apontadas neste estudo de caso. De qualquer forma, os resultados encontrados a partir deste trabalho servem como referência para estudos mais aprofundados que levem a uma maior compreensão sobre o funcionamento de conselhos consultivos e seus diferenciais em comparação com os demais tipos de conselho apresentados na literatura.

${ }^{4}$ Site oficial: http://www.prefeitura.sp.gov.br/cidade/secretarias/desestatizacao/ 


\section{REFERÊNCIAS}

Avritzer, L. (2012, julho). The different designs of public participation in Brazil: deliberation, power sharing and public ratification. Critical Policy Studies, 6(2), 113-127.

Bishop, P., \& Davis, G. (2002, março). Mapping public participation in policy choices. Australian Journal of Public Administration, 61(1), 14-29.

Beltrão, R. E. V., \& Nogueira, F. A. (2011). The documentary research in recent studies in public administration and social management in Brazil. In Anais do $35^{\circ}$ Encontro da ANPAD. Rio de Janeiro, RJ, Brasil.

Casula, M. (2017). Who governs in (local) governance? Theorical considerations and empirical evidence. Revista de Administração Pública, 51(6), 1121-1138.

Crantschaninov, T. I. (2018). Da expectativa à (des)mobilização: a trajetória da participação nas conferências da Defensoria Pública do Estado de São Paulo (Tese de Doutorado). Escola de Administração de Empresas de São Paulo, Fundação Getulio Vargas, São Paulo.

Coelho, V. S. P. (2013). What did we learn about citizen involvement in the health policy process: lessons from Brazil. Journal of Public Deliberation, 9(1), 1-17.

Coelho, V. S. P. (2014). A brief reflection on the Brazilian participatory experience. Journal of Public Deliberation, 10(1), 1-4.

Cohn, A. (2011) Participação social e conselhos de políticas públicas. Brasília, DF: IPEA, 2011. (Texts for discuss CEPAL-IPEA 29).

Cornwall, A. (2006). Introduction: New democratic spaces? The politics and dynamics of Institutionalized Participation. IDS Bulletin, 35(2): 1-10.

Cornwall, A., Coelho, V. S. P. (2006). Spaces for change? The politics of participation in new democratic arenas. In A. Cornwall, \& V. S. P. Coelho (Eds.). Spaces for Change?: The Politics of Citizen Participation in New Democratic Arenas (Claiming Citizenship). London, UK: Zed Books.

Fleury, S. (2006). O Conselho de Desenvolvimento Econômico e Social do governo Lula. In P. E. M. Martins, \& O. P. Pieranti (Eds.). Estado e Gestão
Pública: Visões do Brasil Contemporâneo (2. ed., pp. 79-105). Rio de Janeiro, RJ: Editora FGV.

Lima, P. P. F. et al. (2014). Conselhos Nacionais: elementos constitutivos para sua institucionalização. Brasília, DF: IPEA. (Textos para discussão, n 1951).

Miles, M. B., \& Huberman, A. M. (1994). Qualitative data analysis: an expanded sourcebook (2nd ed.). Thousand Oaks, CA: Sage Publications.

Nobre, M. (2004). Participação e deliberação na Teoria Democrática: uma introdução. In V. S. P. Coelho, \& M. Nobre (Eds.), Participação e deliberação: Teoria democrática e experiências institucionais no Brasil contemporâneo (pp. 21-40). São Paulo, SP: Editora 34.

O’Donnell, G. (1976). Sobre o corporativismo e a questão do Estado. Cadernos do DCP, 3, 1-54.

Pinto, C. R. J. (2004). Espaços deliberativos e a questão da representação. Revista Brasileira de Ciências Sociais, 19, 97-16.

Santos, P. R. (2016) Inovações participativas, diálogo social e construção de consensos. Revista de Administração Pública, 50(3), 501-511.

Souto, A. L. S., \& Paz, R. D. O. (2012). Novas lentes sobre a participação: utopias, agendas e desafios. São Paulo, SP: Instituto Pólis.

Stake, R. E. (2008). Qualitative case studies. In N. K. Denzin, \& Y. S. Lincoln (Eds.), Strategies of qualitative inquiry (pp. p. 119-149). Thousand Oaks, CA: Sage Publications.

Szwako, J. (2012). Participar vale a pena, mas...: a democracia participativa brasileira vista pelas lentes da utopia. In A. L. S. Souto, \& R. D. Paz (Eds.), O. Novas lentes sobre a participação: utopias, agendas e desafios (pp. 13-44). São Paulo, SP: Instituto Pólis.

Teixeira, A. C. C., Souza, C. H. L., \& Lima, P. P. F. (2012). Arquitetura da participação no Brasil: uma leitura das representações políticas em espaços participativos nacionais. In A. L. S. Souto, \& R. D. $\mathrm{Paz}$ (Eds.), O. Novas lentes sobre a participação: utopias, agendas e desafios (pp. 49-76). São Paulo, SP: Instituto Pólis.

Vizeu, F., \& Bin, D. (2008). Democracia deliberativa: leitura crítica do caso CDES à luz da teoria do discurso. Revista de Administração Pública, 42(1), 83-108. 
RAP | Participação consultiva no Brasil: o caso do Conselho da Cidade de São Paulo

Wampler, B. (2010). Transformando o Estado e a Sociedade Civil por meio da Expansão das Comunidades. In L. Avritzer (Ed.), A dinâmica da participação local no Brasil. Brasília, DF: Cortez.

Young, I. M. (2001). Comunicação e o outro: além da democracia deliberativa. In J. Souza (Ed.),
Democracia hoje: novos desafios para a teoria democrática contemporânea (pp. 365-386). Brasília, DF: Editora UNB.

Young, I. M. (2006). Representação política, identidade e minoria. Lua Nova, 67, 139-190.

\section{Fernanda Lima-Silva}

https://orcid.org/0000-0003-4838-7075

Doutora em Administração Pública e Governo pela Escola de Administração de Empresas de São Paulo da Fundação Getúlio Vargas (FGV EAESP). E-mail: fernanda.silva@fgv.br

\section{Kate Abreu}

iD

https://orcid.org/0000-0002-5229-5504

Doutora em Administração Pública e Governo pela Escola de Administração de Empresas de São Paulo da Fundação Getúlio Vargas (FGV EAESP). E-mail: katedayana@gmail.com

\section{Esther M. Leblanc}

https://orcid.org/0000-0002-1885-6195

Mestre em Administração Pública e Governo pela Escola de Administração de Empresas de São Paulo da Fundação Getúlio Vargas (FGV EAESP). E-mail: estherleblanc@gmail.com 
RAP | Participação consultiva no Brasil: 0 caso do Conselho da Cidade de São Paulo

\section{ANEXO 1}

\section{Roteiro da entrevista}

1. Fale brevemente sobre sua carreira profissional e seu papel no Conselho da Cidade de São Paulo.

2. Por que e como o CCSP foi criado?

3. Quais critérios foram usados para a seleção de conselheiros?

4. O CCSP gerencia recursos?

5. O CCSP elabora políticas públicas?

6. O CCSP implementa ou avalia políticas públicas?

7. Quem define os temas discutidos nas reuniões do CCSP?

8. Quais temas aparecem com mais frequência nas reuniões do Conselho da Cidade?

9. Existem pessoas de partidos políticos de oposição ao governo municipal participando do Conselho da Cidade?

10. Na prática, como o CCSP aconselha o prefeito?

11. Na sua opinião, quais os aspectos positivos do CCSP?

12. Na sua opinião, quais os aspectos negativos do CCSP?

13. Quais eram suas expectativas no início de sua participação no CCSP? Suas expectativas foram atendidas? 